\title{
Data Warehouse Menggunakan Snowflake Schema Pada Virtual Shop
}

\author{
Vicky Novreza ${ }^{*}$, Yuda Munarko ${ }^{2}$, Lailatul Husniah \\ 1,2,3 Jurusan Teknik Informatika, Universitas Muhammadiyah Malang \\ vnovreza@gmail.com¹,yuda.munarko@gmail.com², husniah@umm.ac.id ${ }^{3}$
}

\begin{abstract}
Abstrak
Virtual shop adalah penerapan teknologi virtual realiy pada toko online guna meningkatkan interaksi pembeli. Penerarapan virtual reality pada online shop menimbulkan pertanyaan untuk penyimpanan data serta pengolahan data sebagai analisa kebutuhan. Data pada toko online sebatas pada data transaksional dan tidak dilakukan pengolahan yang lebih untuk dilakukan analisa. Solusi dari permasalahan tersebut dengan melakukan perancangan data warehouse untuk menyiapkan tempat penyimpanan data agar analisa dapat dilakukan guna pengembangan teknologi virtual shop. Sistem pada data warehouse dapat sebagai repository data yang digunakan oleh virtual shop. Penelitian ini menerapkan multidimensional snowflakes schema dengan tujuan me-normalisasi tabel dimensi sehingga tidak terjadi redudansi data khusus pada tabel dimensi. Menerapkan metode desain data multidimensional dari Moody pada Multidimensional snowflakes schema, from ER models to Dimensional models. Untuk mendukung penelitian ini, Peneliti melakukan analisis pada data warehouse dengan menggunakan OLAP Cube Reporting berbasis web.
\end{abstract}

Kata Kunci: OLAP, Cube, Snowflake Schema, Data Warehouse, ETL

\begin{abstract}
A Virtual Shop is kind of Online based store that implement Virtual Reality Technology for their interaction. Usually, Data inside online shop just as transactional data and there is not further process to makes that data as analyse need. So, in this research is to design we can call Data Warehouse as a solution to prepare a repository for data to make use as analyse need for Virtual Shop development. This research implement multidimensional scheme is Snowflake Scheme as Moody's from ER models to Dimensional Models for it method. For analysis activities, user will do that activities via Web Based OLAP Cube Reporting.
\end{abstract}

Keywords: OLAP, Cube, Snowflake Schema, Data Warehouse, ETL

\section{Pendahuluan}

Virtual Reality (VR) merupakan bentuk visualisasi terhadap objek environment tiga atau dua dimensi yang dapat dilihat dari berbagai arah sebagai pengguna. Pengguna dapat melakukan interaksi virtual terhadap environment VR. Hal tersebut memungkinkan pengguna untuk merasakan secara rill kedalam suasana virtual sehingga tidak terdapat batasan dalam menjelajah objek environment secara tidak langsung [1]. Batasan yang dimaksud adalah pengguna secara bebas memilih cara menikmati environment pada VR. Karena keunggulan dalam berinteraksi teknologi VR menjadikan VR salah satu objek pengembangan pada untuk berbagai bidang. Salah satu bidang pengembangan adalah penerapan VR kedalam e-commerce.

Penerapan VR pada e-commerce mencetuskan sebuah pengembangan supermarket dengan melakukan interaksi secara virtual atau virtual supermarket. Menurut Wilma waterlander, virtual supermarket adalah sebuap aplikasi yang menggambarkan supermarket secara nyata dalam objek environment tiga dimensi. Aplikasi yang terdiri dari frontend dan backend untuk membagi antara pengguna aplikasi dan kegiatan menejerial. Frontend adalah bagian yang digunakan oleh pengguna aplikasi untuk melakukan interaksi pada virtual supermarket. Sedangkan Backend adalah bagian yang digunakan oleh pemilik dalam melakukan manejerial pada supermarket [2]. Terdapat pertukaran data didalam aplikasi Virtual Supermarket, pertukaran data terjadi antara pengguna dan pemilik dalam prosese e-commerce. Alur pertukaran data yang dilakukan terus-menerus akibat aktifitas yang dilakukan pada virtual supermarket. Sehingga 
diperlukan sebuah basis data untuk melakukan penyimpanan data serta pemilik dapat melakukan pengolahan data.

Berdasarkan rujukan buku Fundamentals of Database System, basis data adalah kumpulan dari relasi data yang terintergerasi [3]. Data dapat dimanfaatkan untuk melakukan analisa kebutuhan pemilik. Sehingga data yang didapat tidak hanya disimpan akan tetapi diolah agar dapat melakukan analisa tentang kinerja sistem. Yang Hao berpendapat bahwa data ecommerce hanya dipersiapkan untuk transasik dan analisi query, serta tidak dapat melakukan penyajian informasi lebih dalam [4]. Maka dibutuhkan sebuah cara yang memungkinkan untuk melakukan penyajian informasi lebih spesifik diperlukan sebuah cara yaitu dengan Data Warehouse

Menurut Yang Hao, data warehouse memungkinkan untuk mencari informasi terkait trend pembelian barang, informasi penjualan barang, informasi kehilangan produk [4]. Data Warehouse merupakan sebuah repositori untuk rekam jejak, terintegrasi dan bersifat konsisten terhadap data yang memungkinkan sebuah manajerial perusahaan untuk menghasilkan informasi yang dapat digunakan untuk proses pendukung pengambil keputusan [5].

Peneliti melakukan eksperimen dengan menggunakan studi kasus virtual shop. Penelitian ini merupakan bagian yang mencakup komponen yang terintergerasi dari satu kesatuan. Peneliti berkontribusi pembangunan data warehouse untuk menjawab permasalah e-commerce dalam VR, yaitu belum adanya repository data yang dapat menyiapkan data guna melakukan analisis tentang kegiatan transaksional penjualan [2]. Solusi yang diajukan peneliti adalah untuk menangani permasalahan tersebut dengan membuat sistem data warehouse pada studi kasus virtual shop. Menyajikan data untuk melakukan analisis pada kegiatan jual-beli pada virtual shop guna melakukan monitoring.

Pada umumnya, data warehouse mayoritas menggunakan Star Schema sebagai paradigma skema yang digunakan. Pada penelitian ini, penulis ingin menggunakan perancangan Data Warehouse menggunakan SnowFlakes Schema pada virtual shop. Penulis menggunakan SnowFlakes Schema adalah skema tersebut dapat me-normalisasi pada tabel dimensi sehingga tidak terjadi redudansi data khususnya pada tabel dimensi. Pada Snowflake Schema, dimensi dilakukan normalisasi ke dalam tabel yang terelasi yang dimana dimensi pada Star Schema terjadi denormalisasi dikarenakan dimensi yang berada hanya pada satu tabel saja [6]. Snowflake juga bisa mengurangi terjadinya redudansi data dikarenakan dimensinya dilakukan pemecahan secara hierarki. Selain itu, pada Snowflake Schema memungkinkan untuk menampilkan data lebih spesifik dari dimensi-dimensi yang ada.

\section{Metode Penelitian}

Berikut merupakan gambaran secara umum sistem Virtual Shop yang dimana terdiri dari 7 bagian. Pada penelitian ini, bagian yang diambil adalah Data Warehouse.

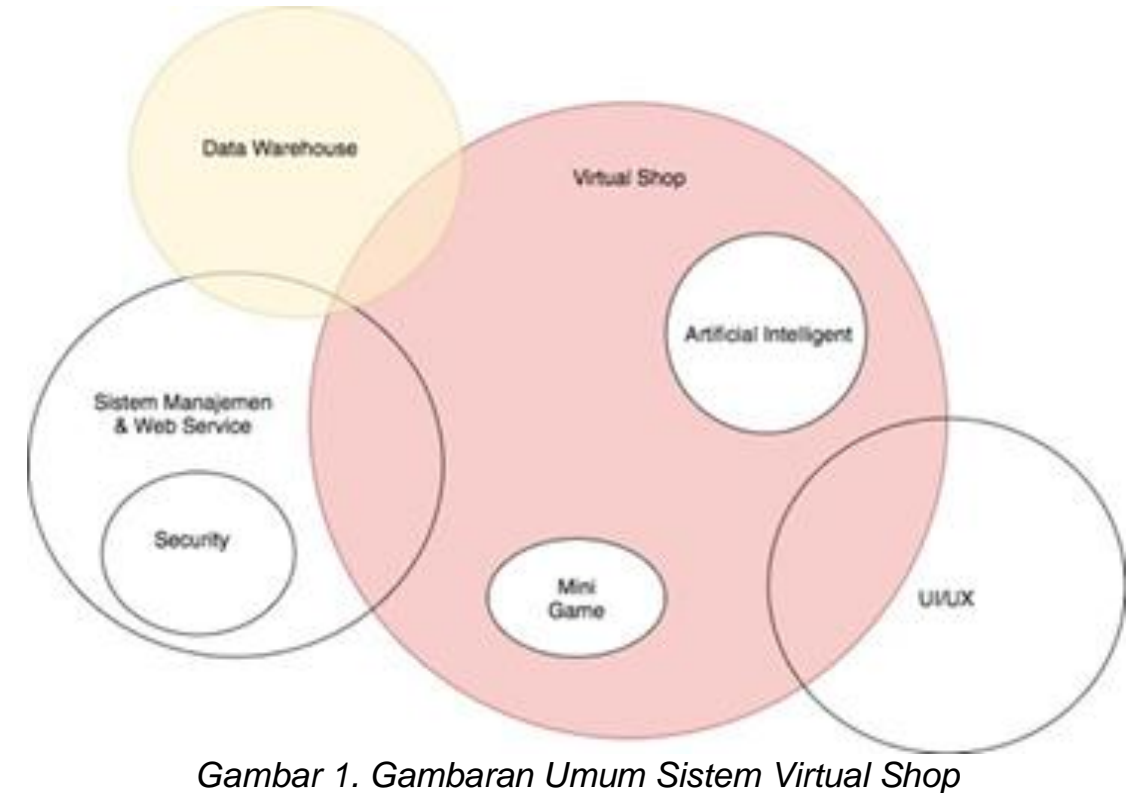

REPOSITOR, Vol. 2, No. 1, Januari 2020: 67-78 
Gambar 1 dapat dilihat tentang gambaran keseluruhan sistem Virtual Shop, penulis akan melakukan penelitian mengenai pembangunan Data Warehouse untuk Virtual Shop. Dalam Pembangunan Data Warehouse dilakukan dalam beberapa tahapan perancangan sesuai dengan metodologi perancangan data warehouse yaitu From ER Models to Dimensional Models dari Moody.

\subsection{ER Diagram Database}

Pada sub bab ini akan dijelaskan rancangan yang berkaitan dengan Diagram OLTP pada Virtual Shop. ER Diagram meliputi ER Diagram pada OLTP Virtual Shop.

\subsection{ER Diagram OLTP Virtual Shop}

ER Diagram OLTP pada Virtual Shop merupakan rancangan yang digunakan pada sistem manajemen Virtual Shop. Rancangan ini merujuk pada penelitian yang dilakukan oleh Gusti Alfian M.P yang berjudul Implementasi Rest dan Sistem Manajemen Pada Virtual Shop. Pada OLTP tersebut memiliki total tabel sebanyak 16 tabel, ditampilkan pada Tabel 1.

Tabel 1. Deskripsi Tabel OLTP Virtual Shop

\begin{tabular}{|c|c|c|}
\hline No. & Nama Tabel & Deskripsi \\
\hline 1 & Buy & $\begin{array}{c}\text { Tabel ini memuat data yang berkaitan dengan transaksi } \\
\text { pembelian }\end{array}$ \\
\hline 2. & Buy_detail & $\begin{array}{l}\text { Tabel ini berisi data yang berkaitan dengan detail } \\
\text { pembelian yang dilakukan }\end{array}$ \\
\hline 3. & Buy_methode & Tabel ini \\
\hline 4. & Confirmation & $\begin{array}{c}\text { Tabel ini berisi data pembelian yang memerlukan } \\
\text { konfirmasi }\end{array}$ \\
\hline 5. & Delivery & $\begin{array}{c}\text { Tabel ini berisi data yang berkaitan dengan progres } \\
\text { pengiriman dari barang yang dibeli }\end{array}$ \\
\hline 6. & Location & $\begin{array}{c}\text { Tabel ini berisi data yang berkaitan dengan lokasi dari } \\
\text { user }\end{array}$ \\
\hline 7. & Placement & $\begin{array}{c}\text { Tabel ini berisi data yang berkaitan dengan penempatan } \\
\text { barang yang ada }\end{array}$ \\
\hline 8. & Price_history & $\begin{array}{c}\text { Tabel ini berisi data yang berkaitan dengan perubahan } \\
\text { harga pada barang yang dijual }\end{array}$ \\
\hline 9. & Product & $\begin{array}{c}\text { Tabel ini berisi data yang berkaitan dengan deskripsi } \\
\text { umum produk yang dijual }\end{array}$ \\
\hline 10 & Product_discount & Tabel ini berisi data yang berkaitan dengan \\
\hline 11. & Product_location & $\begin{array}{l}\text { Tabel ini berisi data yang berkaitan dengan lokasi produk } \\
\text { berada }\end{array}$ \\
\hline 12. & Product_price_list & $\begin{array}{c}\text { Tabel ini memuat data berkaitan dengan list harga pada } \\
\text { produk yang dijual }\end{array}$ \\
\hline 13. & Product_type & $\begin{array}{c}\text { Tabel ini memuat data yang berkaitan dengan tipe } \\
\text { produk }\end{array}$ \\
\hline 14. & Promotion & $\begin{array}{c}\text { Tabel ini memuat data yang berkaitan dengan promosi } \\
\text { yang berlaku pada produk }\end{array}$ \\
\hline $\begin{array}{l}15 . \\
16 .\end{array}$ & $\begin{array}{l}\text { Region } \\
\text { User }\end{array}$ & $\begin{array}{l}\text { Tabel ini memuat data regional dari user } \\
\text { Tabel ini memuat data deskripsi user }\end{array}$ \\
\hline
\end{tabular}

Pada rancangan OLTP tersebut akan di kondisikan sesuai dengan paradigma skema data warehouse yang akan digunakan yaitu Snowflake Schema dengan menerapkan metodologi perancangan data warehouse From ER Models to Dimensional Models dari Moody.

Pada Gambar 2 dapat dilihat bahwa pada tabel Product_discount terdapatnya kolom condition_type dan condition. Kondisi tersebut dapat menyebabkan terjadinya perulangan data atau bisa disebut dengan redundansi data. Pada penelitian ini menerapkan paradigma snowflake schema sehingga tabel OLTP tersebut perlu dilakukan pengkondisian dengan melakukan normalisasi. Normalisasi yang dapat dilakukan adalah melakukan pemecahan pada tabel tersebut sehingga terbentuk tabel baru berdasarkan kolom tersebut. 


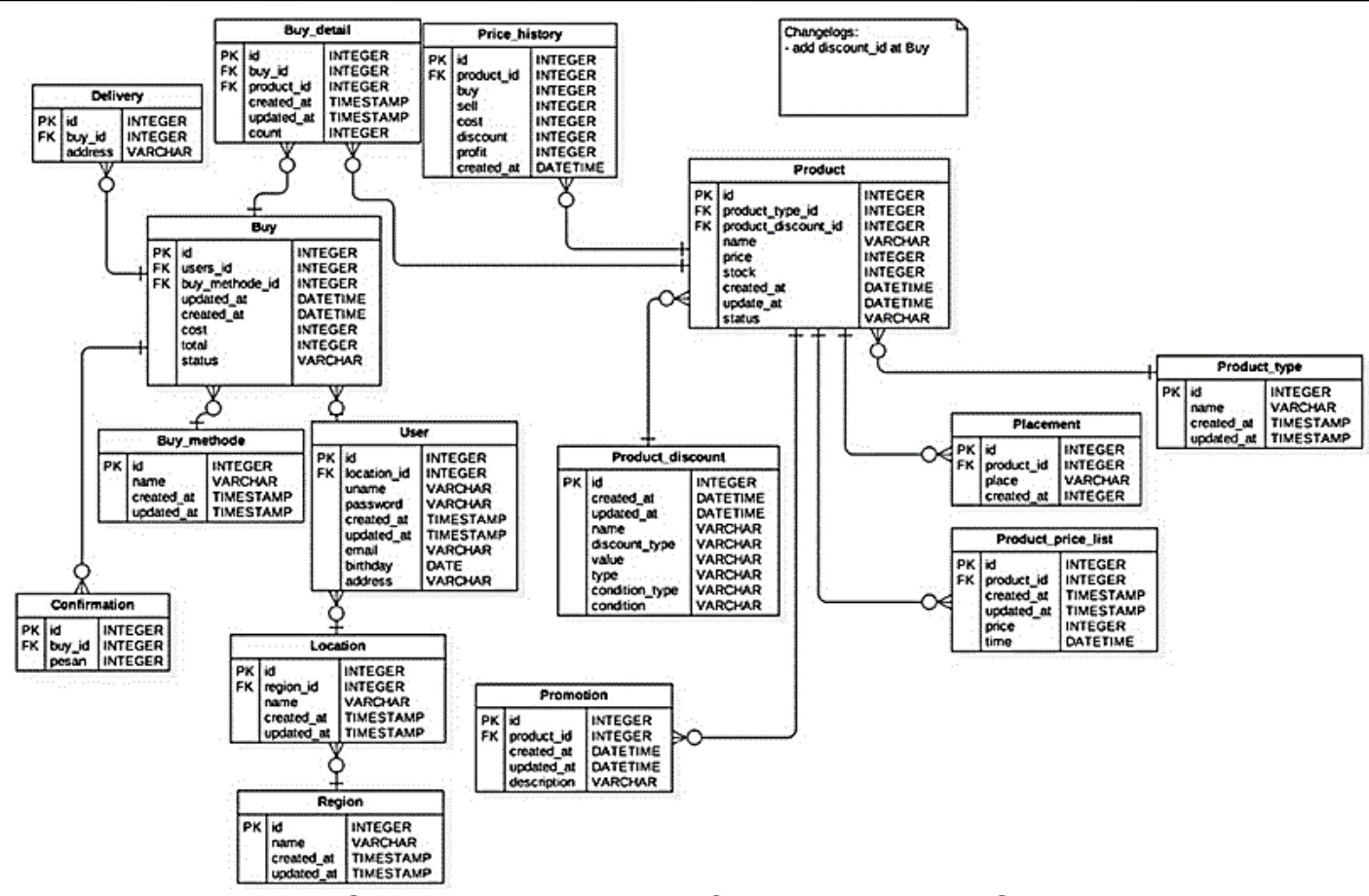

Gambar 2. ER Diagram OLTP pada Virtual Shop

\subsection{Metode From ER Model to Dimensional Model}

Pada metode ini terdapat empat langkah utama dalam melakukan perancangan data warehouse [7]. Pada sub bab berikut ini akan dijelaskan masing-masing tahapan tersebut

\subsection{Entitas Klasifikasi}

Pada bagian ini akan dilakukan pembagian entitas sesuai dengan rancangan OLTP pada Virtual Shop. Pembagian entitas ada tiga jenis antara lain, Entitas Transaksi, Entitas Komponen, dan Entitas Klasifikasi [7]. Gambar 3 adalah gambaran pembagian entitas berdasarkan diagram OLTP Virtual Shop.

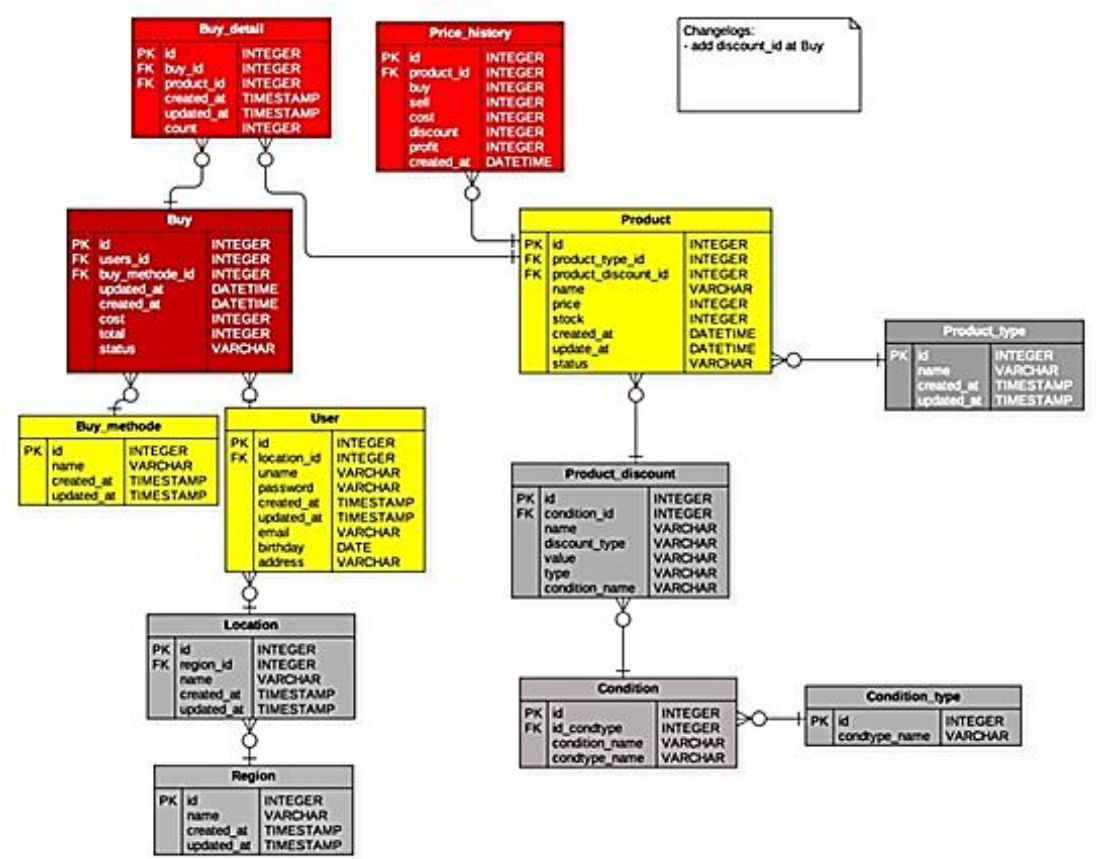

Gambar 3. Pembagian Entitas pada Diagram OLTP Virtual Shop

REPOSITOR, Vol. 2, No. 1, Januari 2020: 67-78 


\subsection{Identifikasi Hierarki (Identify Hierarchies)}

Pada tahap ini dilakukan identifikasi hierarki sesuai pada tahapan sebelumnya. Identifikasi hierarki dilakukan untuk membentuk model dimensi / tabel dimensi dari ER OLTP yang ada (moody).

\subsection{Hierarki Maksimal}

Hierarki maksimal adalah sebuah kondisi entitas yang tidak dapat dilakukan ekspansi keatas ataupun kebawah dengan menyertakan entitas lain. Pada penelitian ini, terdapat 6 hierarki maksimal yaitu

1. product_type, product, price_history

2. product_type, Product, Buy_detail

3. condition_type, condition, product_discount, product, price_history

4. condition_type, condition, product_discount, product, buy_detail

5. region, location, user, buy, buy_detail

6. buy methode, buy, buy_detail

Berdasarkan pada penjelasan tersebut, bisa dilakukan kategorisasi entitas. Tabel yang masuk pada hierarki Entitas Minimal adalah tabel product type, condition_type, region dan buy_methode. Sedangkan tabel yang masuk pada hierarki Entitas Maksimal adalah tabel price_history dan buy_detail.

Tahap ini juga memiliki fungsi untuk melakukan identifikasi tabel mana yang berada posisi paling bawah dan paling atas sehingga dapat mempermudah dalam melakukan identifikasi tabel sub-dimensi, dimensi dan tabel fakta.

\subsection{Perancangan Dimensional (Produce Dimensional Models)}

Pada tahap ini dilakukan pembentukan model dimensional dari ER OLTP berdasarkan pada proses-proses yang dilakukan sebelumnya yang ada. Terdapat 2 operator yang dilakukan pada tahap ini yaitu operator Collapse Hierarchy (Peleburan Hierarki) dan Aggregates Operator (Operator Aggregasi/perhitungan).

\subsection{Collapse Hierarchy (Peleburan Hierarki)}

Pada penelitian ini tidak diperlukan peleburan hierarki dikarenakan skema yang digunakan adalah snowflake schema sehingga tabel pada entitas minimal tidak dilakukan tindakan apapun.

\subsection{Aggregates Operator (Operasi Aggregasi/Perhitungan)}

Pada operator Agregasi tidak dilakukan dikarenakan pada setiap kolom yang ada pada entitas transaksi sudah mewakili perhitungan yang dibutuhkan.

Pada tahap ini dapat ditunjukkan hasil perancangan skema OLAP dari beberapa proses sebelumnya pada setiap transaksi yang ada dalam bentuk Snowflake Schema.

\subsection{Evaluasi dan Perbaikan (Evaluation and Refinement)}

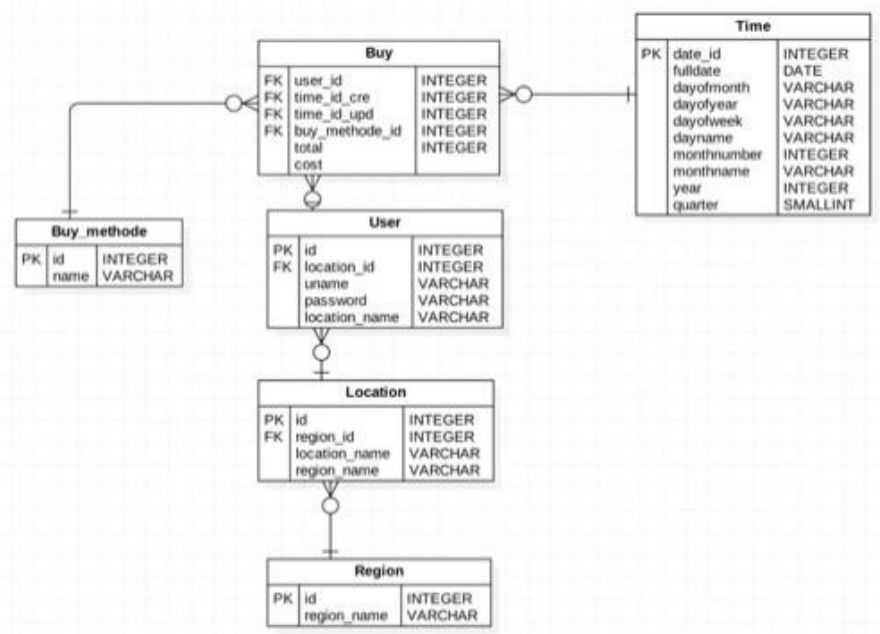

Gambar 4. Skema OLAP Fakta Buy

Data Warehouse Menggunakan Snowflake Schema... Vicky Novreza, Yuda Munarko, Lailatul Husniah 


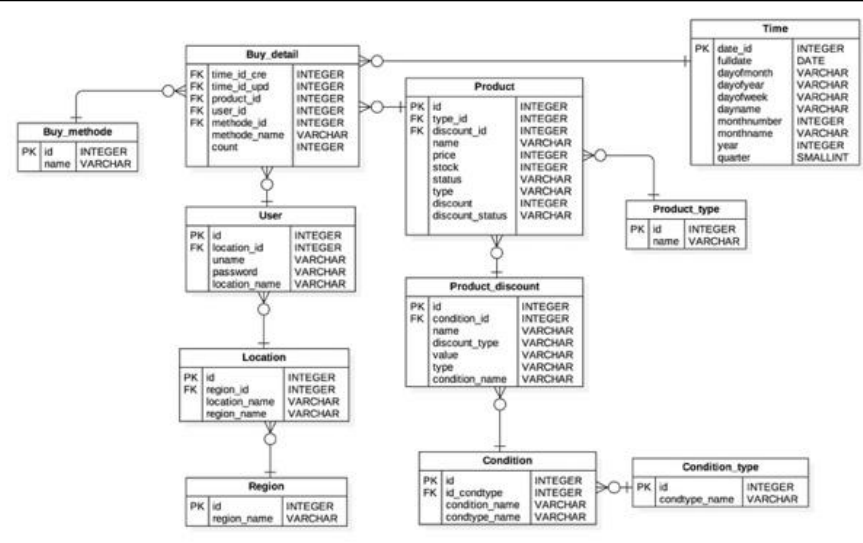

Gambar 5. Skema OLAP Fakta Buy_detail

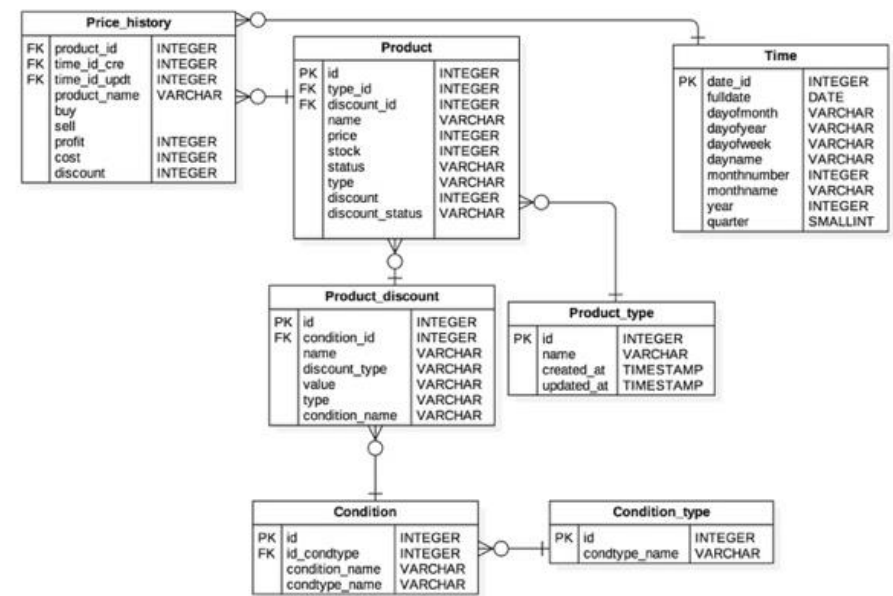

Gambar 6. Skema OLAP Fakta Price_history

Tahap Evaluasi dan Perbaikan adalah tahap terakhir dari metode ER Models to Dimensional Models. Setelah dilakukan perancangan pada tahap-tahap sebelumnya, dilakukan sebuah evaluasi apakah rancangan yang dihasilkan sudah sesuai atau tidak. Rancangan OLAP yang sesuai menurut moody adalah tidak adannya pola non-hierarki pada entitas yang ada (moody). Pada rancangan OLAP Virtual Shop sudah sesuai dan bersifat hierarki pada setiap entitas yang ada sehingga tidak diperlu dilakukan tindakan pada tahap ini. Skema OLAP yang dihasilkan dari beberapa proses tersebut dapat dilihat pada Gambar 4, Gambar 5, dan Gambar 6.

\section{Hasil Penelitian dan Pembahasan}

Tahapan implementasi yang dilakukan dan pengujian yang dilakukan pada penelitian ini untuk mengetahui bahwa sistem berjalan dengan baik. Implementasi meliputi melakukan ETL (Extract, Transform, Loading) pada OLAP yang sudah dirancang, pembuatan Cube OLAP, dan pembuatan web based report. Pengujian meliputi pengujian pada kegiatan ETL.

\subsection{Persiapan}

Pada penelitian ini implementasi dilakukan dengan melakukan kegiatan ETL terlebih dahulu pada rancangan yang telah dilakukan pada bab sebelumnya. ETL dilakukan dengan menggunakan aplikasi Talend Open Studio For Data Integration. Untuk dapat menjalankan kegiatan tersebut, dibutuhkan perangkat komputer dan local web server untuk melakukan koneksi database.

\subsection{Lingkungan Pengembangan Perangkat Lunak}

Perangkat lunak yang digunakan untuk melakukan implementasi pada penelitian ini adalah sebagai berikut:

REPOSITOR, Vol. 2, No. 1, Januari 2020: 67-78 
1. Sistem Operasi Apple MacOS Sierra 10.12.5 64bit

2. Talend Open Studio For Data Integration untuk melakukan ETL (Extract Transform, Loading)

3. Pentaho Schema Workbench untuk melakukan pembentukan Cube OLAP

4. Pentaho BI Server untuk menampilkan report OLAP Cube berbasis web

\subsection{Lingkungan Pengembangan Perangkat Keras}

Untuk perangkat keras yang digunakan untuk melakukan implementasi pada penelitian ini adalah sebuah $P C$ atau Notebook. Untuk detail dari spesifikasi yang digunakan akan dijelaskan pada Tabel 2.

Tabel 2. Daftar Perangkat Keras yang Digunakan

\begin{tabular}{ccc}
\hline No. & Perangkat Keras & Spesifikasi Perangkat Keras (Notebook) \\
\hline 1. & Processor & Intel Core i5 2.7 GHz \\
2. & RAM & 8 GB 1867 Mhz DDR 3 \\
3. & Resolusi Layar & $2560 \times 1600$ \\
4. & VGA & Intel Iris Graphics $61001536 \mathrm{MB}$ \\
5. & Hard Disk & 128 GB Flash Storage / SSD \\
\hline
\end{tabular}

\subsection{Proses ETL (Extraction, Transform, Load)}

Langkah awal dalam implementasi pada penelitian ini adalah melakukan ETL (Extraction, Transform, Load). Proses ETL seperti pada Gambar 7 terdiri dari Extract yang berarti melakukan ekstraksi data dari sumber data yang digunakan, pada konteks ini adalah database Virtual Shop menggunakan Mysql sebagai database server, nama database yang digunakan adalah vsOLTP. Proses ETL berikutnya adalah Transform yang dimana dilakukan proses transformasi agar database-database operasional terintegrasi menjadi satu bentuk ke dalam suatu database yang disebut dengan OLAP. Langkah terakhir adalah Load yang dimana pada tahap ini dilakukan load ke dalam database rujukan sebagai OLAP database, nama database yang digunakan untuk OLAP adalah VS_DW. Proses ETL dilakukan pembentukan file job ETL menggunakan tools Talend Studio For Data Integration. Pada penelitian ini menghasilkan 12 job ETL yaitu Dim_Buymethode, Dim_Condition_type, Dim_Condition,,Dim_Location, Dim_product_discount, Dim_product_type, Dim_product, Dim_region, Dim_user, Fact_Buy, Fact_Buydetail, dan Fact_Pricehistory.

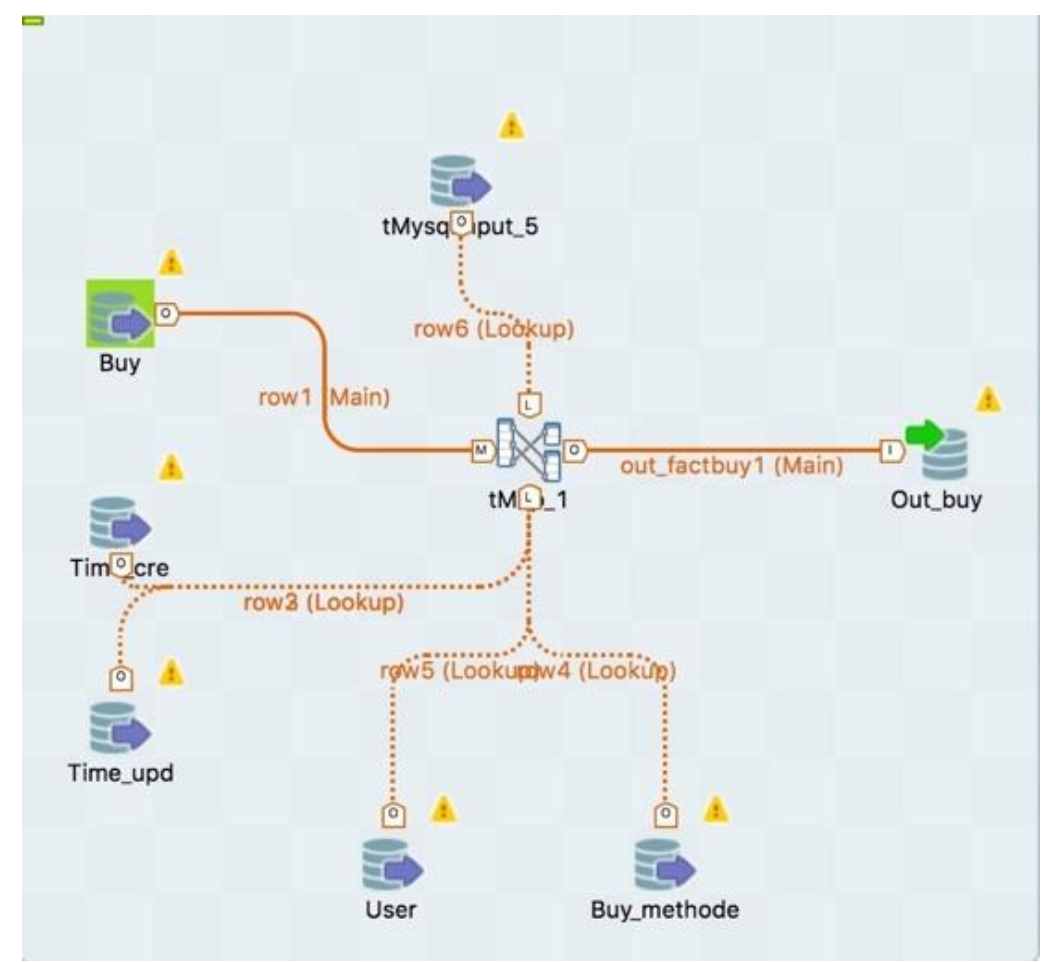

Gambar 7. Skema ETL Job Fact_Buy

Data Warehouse Menggunakan Snowflake Schema... Vicky Novreza, Yuda Munarko, Lailatul Husniah 
3.5 Pembentukan Cube OLAP Virtual Shop

Pada OLAP yang sudah dibangun akan dilakukan pembentukan Cube menggunakan tools Pentaho Schema Workbench, seperti pada Gambar 8.

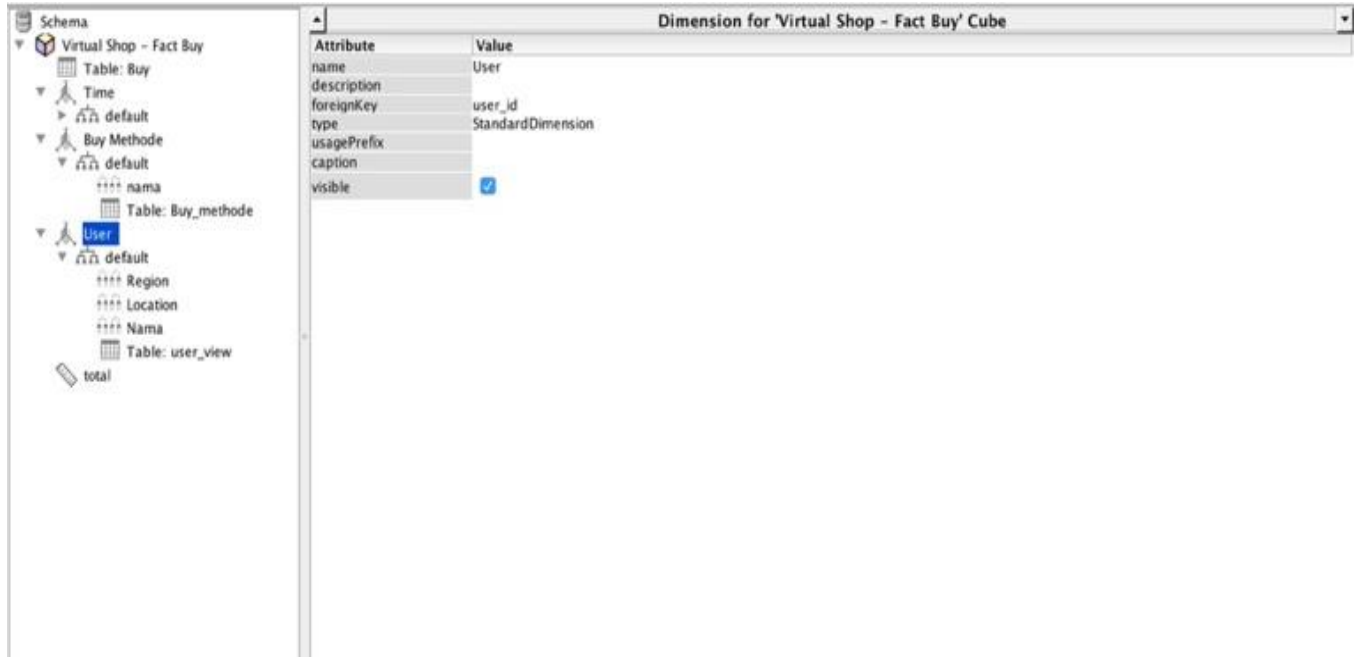

Gambar 8. Struktur Cube OLAP Tabel Fakta Buy Virtual Shop di Pentaho Schema Workbench

\subsection{Reporting OLAP Cube Pada Web}

Pada Gambar 9, yang mana tahap ini dilakukan pembentukan reporting OLAP Cube pada web. Tools yang digunakan untuk membangun reporting OLAP Cube adalah Pentaho BI Server.

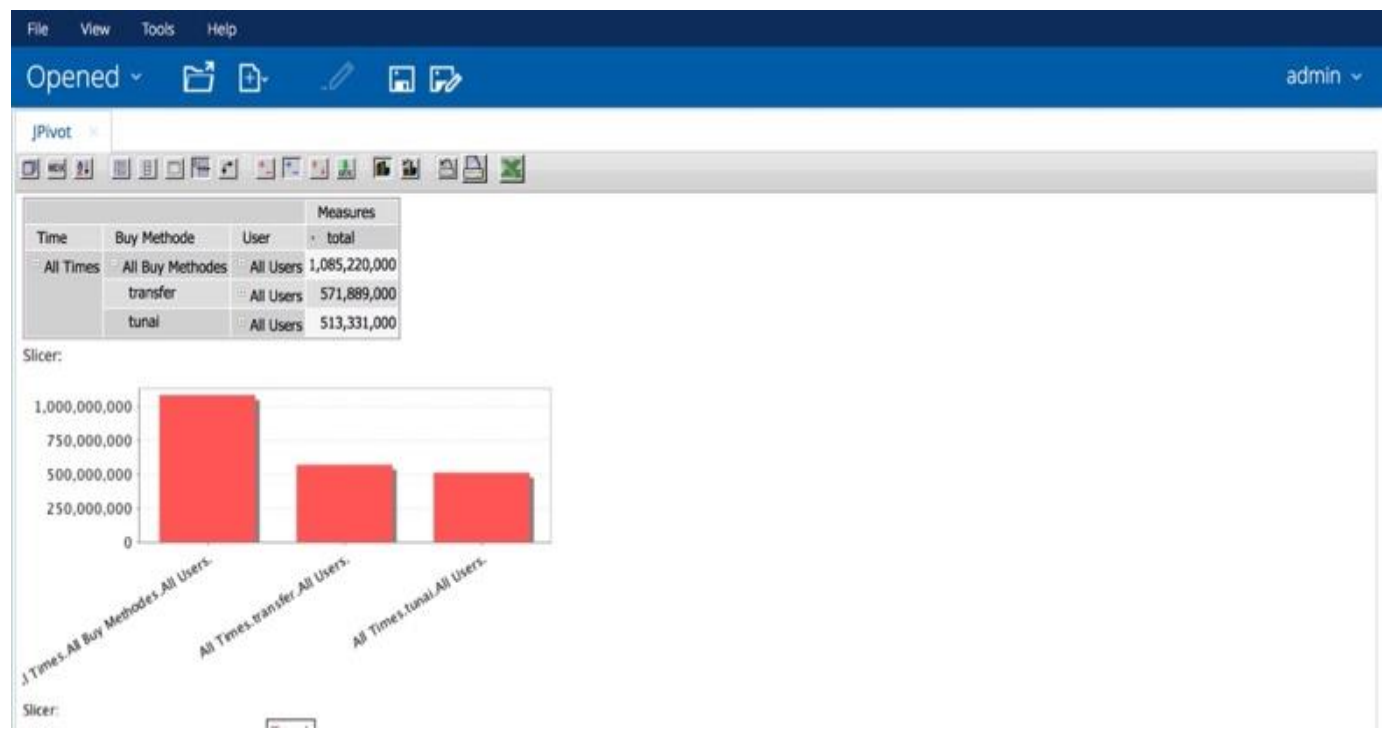

Gambar 9. Cube OLAP Reporting Dashboard

\subsection{Pengujian}

Pengujian yang dilakukan dengan 2 tahap yaitu Verifikasi dan Validasi. Tahap Verifikasi meliputi pengujian pada transformasi ETL yang dilakukan. Tahap Validasi meliputi pengujian apakah data yang di muat ke dalam data warehouse sesuai atau tidak dengan data sumber.

\subsection{Verifikasi Error Pada Job ETL}

Pengujian pada Tabel 3 ini dilakukan dengan melihat keberhasilan proses transformasi yang ada. Kegiatan transformasi yang akan di uji adalah transformasi ETL pada fakta Buy, fakta Buy_detail, dan fakta Price_history.

REPOSITOR, Vol. 2, No. 1, Januari 2020: 67-78 
Tabel 3. Verifikasi Pada Masing-Masing job ETL

\begin{tabular}{|c|c|c|c|}
\hline No & Job ETL & Screenshot & Keterangan \\
\hline 1. & Fact_Buy & $\begin{array}{l}\text { Starting job Fact Buy at } 06: 5011 / 01 / 2018 \text {. } \\
\text { [statistics] connecting to socket on port } 3374 \\
\text { [statistics] connected } \\
\text { [statistics] disconnected } \\
\text { Job Fact Buy ended at } 06: 51 \text { 11/01/2018. [exit code=0] }\end{array}$ & $\begin{array}{l}\text { Hasil eksekusi job Fact_Buy } \\
\text { tidak mengalami error dan } \\
\text { Status Exit Code }=0\end{array}$ \\
\hline 2. & $\begin{array}{c}\text { Fact } \\
\text { Buy_detail }\end{array}$ & $\begin{array}{l}\text { Starting job Pact Buydetail at 06:51 11/01/2018. } \\
\text { [statistics] connecting to socket on port } 3590 \\
\text { [statistics] connected } \\
\text { [statistics] disconnected } \\
\text { Job Fact Buydetail ended at 06:51 11/01/2018. [exit code=0] }\end{array}$ & $\begin{array}{l}\text { Hasil eksekusi job } \\
\text { Fact_Buy_detail tidak } \\
\text { mengalami error dan Status } \\
\text { Exit Code }=0\end{array}$ \\
\hline 4. & $\begin{array}{c}\text { Fact } \\
\text { Price_history }\end{array}$ & $\begin{array}{l}\text { Starting job Fact Pricehistory at 06:52 11/01/2018. } \\
\text { [statistics] comnecting to socket on port } 4016 \\
\text { [statistics] connected } \\
\text { [statistics] disconnected } \\
\text { Job Pact Pricehistory ended at } 06: 52 \text { 11/01/2018. [exit code=0] }\end{array}$ & $\begin{array}{l}\text { Hasil eksekusi job } \\
\text { Price_history tidak } \\
\text { mengalami error dan Status } \\
\text { Exit Code }=0\end{array}$ \\
\hline
\end{tabular}

\subsection{Verifikasi Incremental Load Tabel Fakta Buy}

Pada Gambar 10, pengujian ini dilakukan verifikasi Incremental Load pada tabel fakta Buy apakah sudah sesuai atau tidak. Hasil yang didapatkan tidak ada row yang di extract ketika data yang diinput sudah ada pada database OLAP. Hal tersebut membuktikan bahwa proses Incremental Load berhasil.

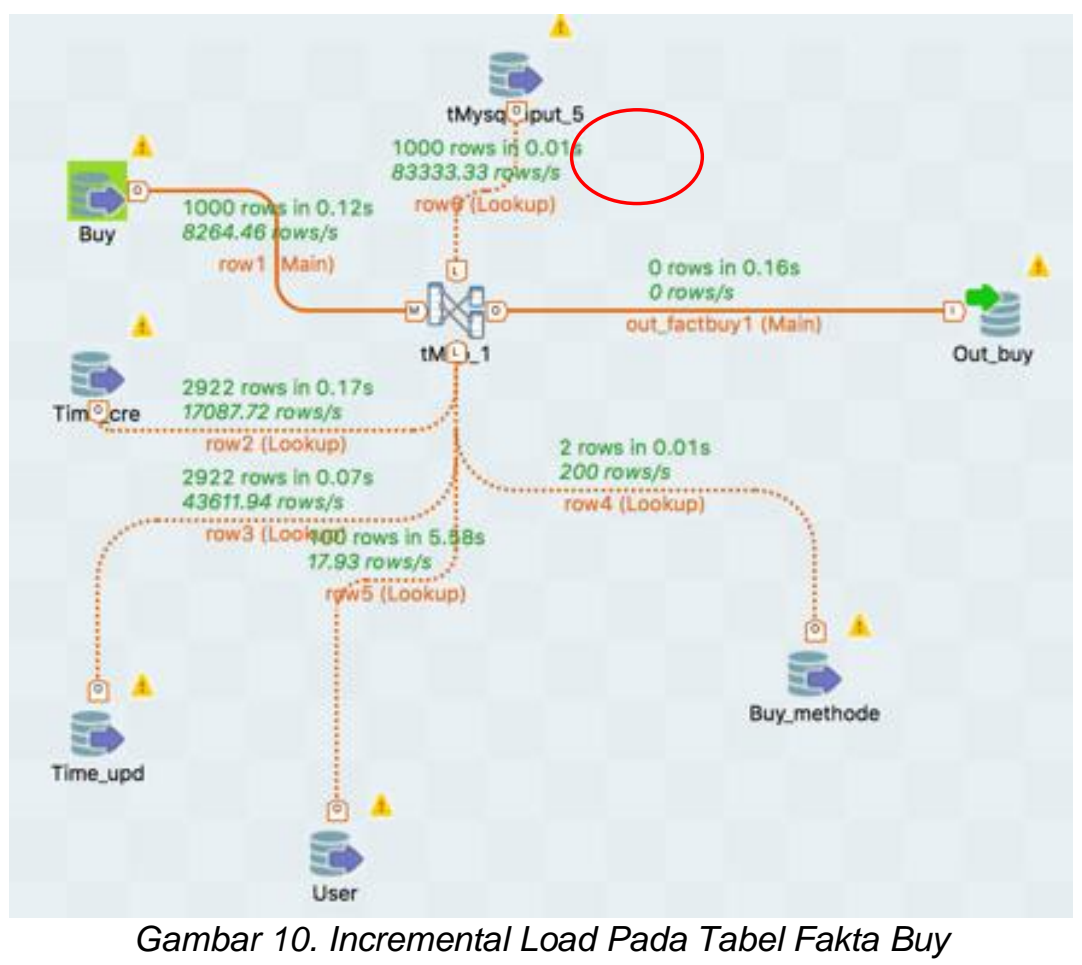

\subsection{Verifikasi Incremental Load Tabel Fakta Buy_detail}

Pada Gambar 11, pengujian ini dilakukan verifikasi Incremental Load pada tabel fakta Buy_detail apakah sudah sesuai atau tidak. Hasil yang didapatkan tidak ada row yang di extract ketika data yang diinput sudah ada pada database OLAP. Hal tersebut membuktikan bahwa proses Incremental Load berhasil. 


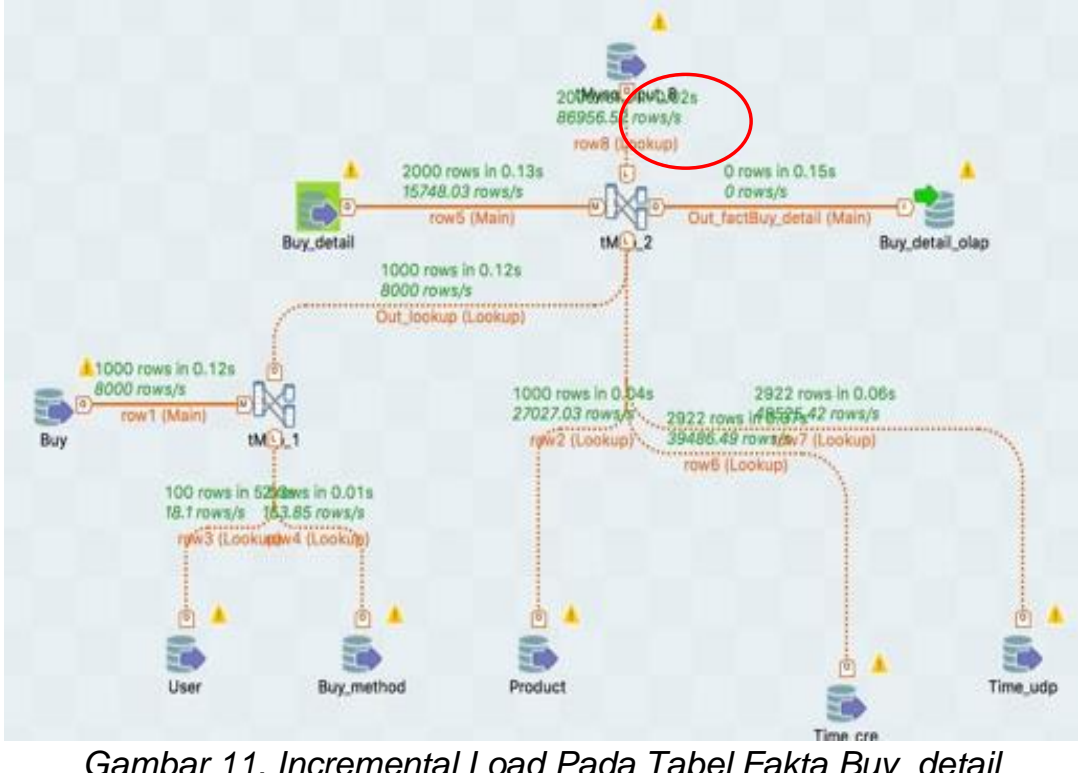

\subsection{Verifikasi Incremental Load Tabel Fakta Price_history}

Pada pengujian Gambar 12 ini dilakukan verifikasi Incremental Load pada tabel fakta Price_history apakah sudah sesuai atau tidak. Hasil yang didapatkan tidak ada row yang di extract ketika data yang diinput sudah ada pada database OLAP. Hal tersebut membuktikan bahwa proses Incremental Load berhasil.

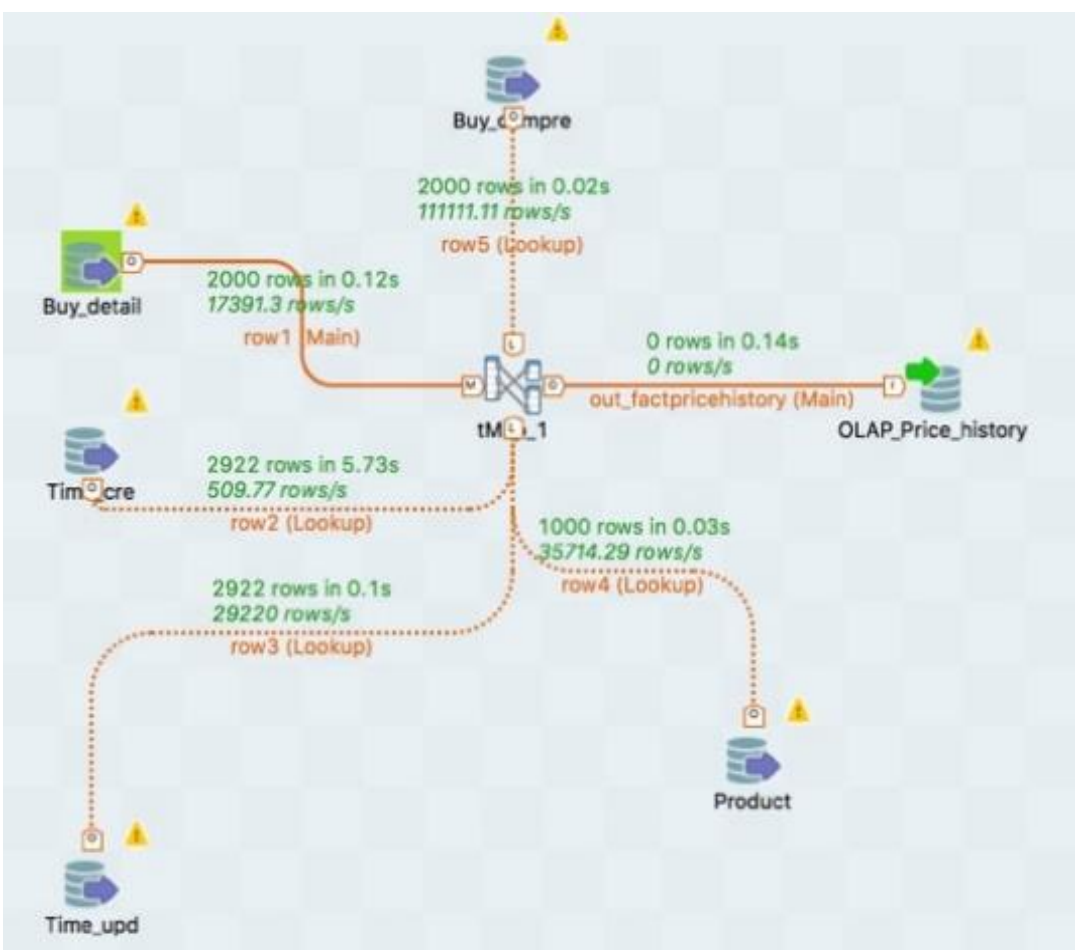

Gambar 12. Incremental Load Pada Tabel Fakta Price_history

\subsection{Pengujian Nilai Data Pada DBMS}

Pada Gambar 13, pengujian ini dilakukan pemeriksaan nilai data sebelum dilakukan transformasi $E T L$ dan setelah dilakukan transformasi $E T L$. Tabel sampel yang dipilih untuk dilakukan pengujian adalah tabel fakta Buy,

REPOSITOR, Vol. 2, No. 1, Januari 2020: 67-78 


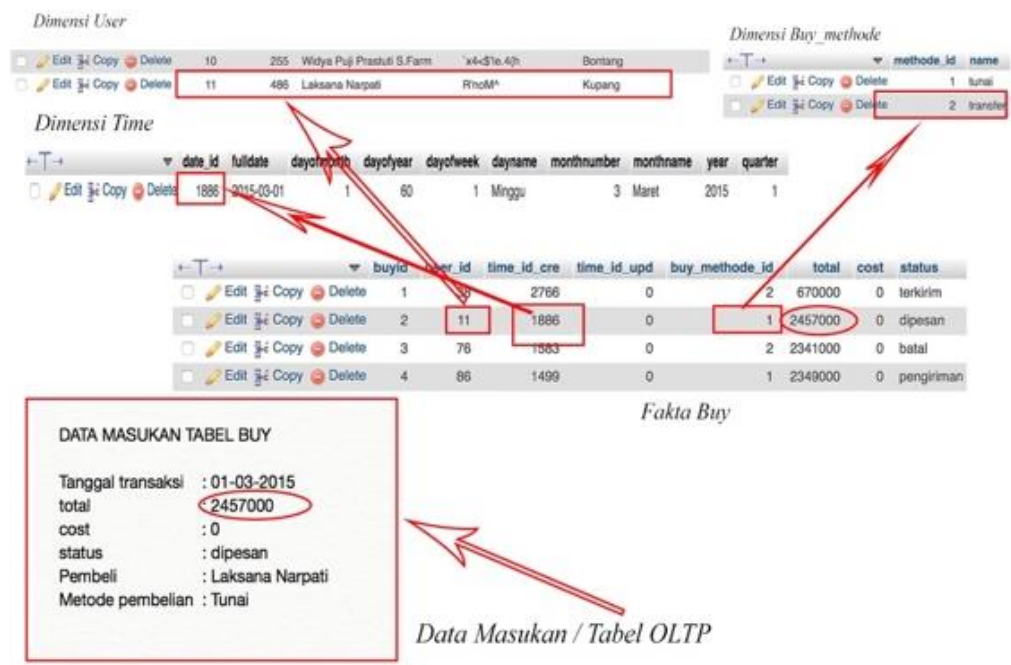

Gambar 13. Pengecekan Nilai Data Pada DBMS

Berdasarkan pengujian yang telah dilakukan, data pada tabel fakta sesuai dengan data pada tabel OLTP / masukan sehingga bisa dikatakan valid.

\section{Kesimpulan}

Dari hasil penelitian "Data Warehouse Menggunakan Snowflake Schema Pada Virtual Shop" ini, dapat disimpulkan sebagai berikut:

1. Rancangan Data Warehouse menggunakan paradigma Snowflake schema membuat rancangan diagram OLAP lebih terstruktur dan dapat terhindar dari terjadinnya redundansi data pada tabel yang ada.

2. Dashboard OLAP Reporting berbasis web yang dibangun menggunakan Pentaho BI Server dengan penggunaan modul jPivot dapat membantu pihak manajerial Virtual Shop dalam melakukan analisis data transaksional pada Cube OLAP yang sudah dibentuk baik dalam bentuk grafik maupun tabel pivot tanpa perlu menggunakan aplikasi tambahan.

3. Penggunaan Data Warehouse dapat membantu dalam menyediakan data yang dapat digunakan untuk keperluan analisis sesuai fakta yang dibentuk dari data operasional yang ada.

4. Penggunaan metode perancangan data warehouse From ER to Dimensional Model oleh Moody dapat mempermudah melakukan perancangan data warehouse yang dibangun dari ER Diagram database operasional.

5. Pengujian verifikasi memberikan hasil bahwa seluruh Job ETL yang sudah dibentuk tidak terjadi error dan fungsi yang terkait berjalan sesuai harapan sehingga dapat digunakan dengan baik.

6. Pengujian validasi memberikan hasil bahwa data pada tabel fakta dan dimensi yang terkait adalah valid.

\subsection{Saran}

Dari penulis ada beberapa saran yang bisa digunakan untuk penelitian selanjutnya.

1. Melakukan perancangan data warehouse menggunakan paradigma skema selain Snowflake agar didapatkan paradigma yang lebih sesuai dengan kebutuhan. Misalnya Constelation, Terraced Schema, Galaxy Schema, dsb.

2. Menambahkan sistem DSS atau Data Mining Forecasting agar penyajian data lebih intuitif.

\section{Referensi}

[1] Ailing Qi, Huan Wang, Wenhui Kang, and Haiyan Wu, "Study on Realization Technology of Virtual Reality for Coal Mining Face," Proceedings of the IEEE International Conference on Information and Automation Ningbo, China, August 2016, vol. III, no. 16, pp. 1218 - 1222 , 2016. 
[2] Wilma Waterlander, Cliona Ni Mhurchu and Ingrid Steenhuis, "The Use of Virtual Reality in Studying Complex Interventions in Our Every-Dat Food Environtment," Virtual Reality Human Computer Interaction, vol. II, no. 11, pp. 229 - 260, 2012.

[3] Ramez Elmasri, Shamkant B. Navathe, Fundamentals Of Database Systems, vol. VI, Boston: Addison-Wesley, 2011.

[4] YANG Hao, SONG Hongwei, and Zhang Zili, "The Application of e-commerce System based on data warehouse," Information Technology and Artificial Intelligence Conference (ITAIC), 2011 6th IEEE Joint International, no. 11, pp. 493-496, 2011.

[5] Matteo Golfarelli, Steffano Rizzi, Data Warehouse Design : Modern Principles and Methodologies, New Delhi: Tata McGraw Hill Education, 2009.

[6] Yebai Li, Xiumei Yu and Cui Li, "The Applied Research on the Statistic Data Warehouse Based on the Snowflake Mode," Database Technology and Applications (DBTA), 2010 2nd International Workshop on, no. 10, pp. 50-62, 2010.

[7] Daniel L. Moody, Mark A.R. Kortink, "From Enterprise Models to Dimensional Models: A Methodology for Data Warehouse and Data Mart Design," Proceedings of the International Workshop on Design and Management of Data Warehouses (DMDW'2000), no. 5, pp. 1-12, 2000.

REPOSITOR, Vol. 2, No. 1, Januari 2020: 67-78 